\title{
Features of the Mongolian Electricity Market
}

\author{
Bat-Ochir Batzaya ${ }^{1, *}$ and Choijiljav ${ }^{1}$ \\ ${ }^{1}$ MUST, Electrical Engineering Department, Mongolia
}

\begin{abstract}
Energy is one of the basic sectors of the country's development. It is closely related with all sectors of the economy, providing the possibility of their stable development including mining, manufacturing, agriculture, transport, communications and others.
\end{abstract}

Keywords. Model single buyer, energy, electricity market.

\section{Introduction}

There are many different electricity market designs in use around the world. Each component of the market design is described briefly below $[1,2,3]$.

Monopoly Model. Monopoly at all levels. One entity may have responsibility for all functions, or the distribution companies may be separate bodies from the generation and transmission entity. This model was in common use around the World prior to the introduction of Independent Power Projects.

Single Buyer Model. A single wholesale buyer of electricity can choose from a number of different generators encouraging competition in generation. Access to the transmission system is not permitted for sales to final consumers. The single buyer model was in common use around the World following the introduction of IPPs.

Wholesale Competition Model. Wholesale buyers (distribution companies and in some cases, large customers directly connected to the transmission networks) can choose their supplier, bringing competition into generation and wholesale supply. This requires open access to the transmission system. Distribution companies maintain a monopoly over retail consumers.

Retail Competition Model. All customers can choose their supplier. This requires open access to the transmission system and distribution systems. The distribution activity can be separated into wires (asset management) and retail, or supply, activities, with the latter being competitive.

\section{Electricity market in Mongolia}

Electricity is the primary industry that affects economic development and competitiveness. Each country, by virtue of its specifics, with respect to its geographical location, natural resources and economic potential, develops an energy policy and determines its own market model.

The energy sector of Mongolia consists of four independent electric power systems:

- Central Energy System (CES),

- Western Energy System (WES),

- Eastern Energy System (EES),
- Altai-Uliastai energy system (AUES).

The main Mongolian electric system is the CES representing $80 \%$ of all Mongolian electricity supply $[4,5]$.

Energy production, before reaching the end user, passes through multiple stages, which includes, in particular, the extraction, transportation and storage of raw materials, the conversion of primary reserve energy into the electric heat, transmission of generated electricity via high voltage lines and their transformation for distribution according to the specific needs of the user. At each of these stages, it is possible to introduce competition mechanisms, from which such a variety of market models derive.

Since the crisis in the basic sector of the economy had reached a level that could have the most negative impact on the entire course of economic reforms, significant adjustments were made to the state energy policy in 2001 . The "Energy Law" was re-adopted and structural changes were made in the industry. The cornerstone of these structural changes was the issue of transferring the functions of energy regulation to an independent institution [6]. Important was the realization of economic management methods at enterprises, and support of the private sector for developing profitable small-scale systems, which became possible due to the undertaking of the following concrete measures:

- resolution of credit and debt problems of enterprises involved in fuel and energy production;

- intensification of work on collecting underpayments from consumers and making changes to the system;

- decrease in technical and commercial losses during the transmission and provision of electric energy;

- changes in price and tariff structures, establishment of fully self-sustaining prices and tariffs;

- reducing the volume of electricity imports and improving the management of external debt.

As for the regulation of the energy market, it is under the control of the Energy Regulatory Committee, the National Dispatch, and the Metropolitan Energy Regulatory Council.

* Corresponding author: z zaya12@mail.ru 
The National Central Dispatch Center plays the role of coordination by providing integrated technological management of the entire energy market.

As for economic issues, the Energy Regulatory Committee resolves them, including those related to the participation of economic organizations in the market relations, as well as matters on prices and tariffs for energy-bearing and other regulated services, and questions about the standards for consumer services.

According to this model, payments made to consumers are accumulated in a bank single income account with a zero balance (figure 1). Moreover, on the same day, according to a coefficient determined by the Energy Regulatory Committee, it is distributed to the accounts of the generating company, as well as transmission and distribution companies. This mechanism creates the fairest basis for the distribution of income between all participants in the energy business, since the specific costs of each company are taken into account depending on forecasts for production and consumption $[7,8]$.

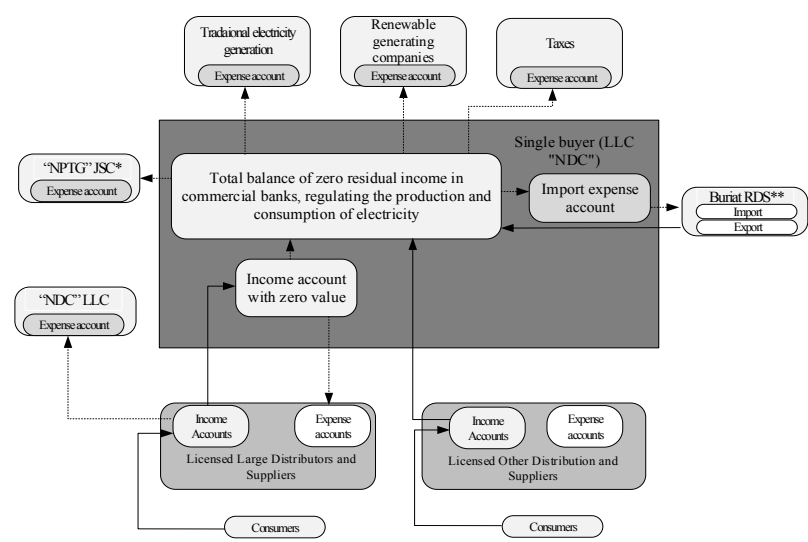

Fig. 1. Cash flow the models "Single Bayer"

* National Power Transmission Grid, **Regional Dispatch Services

Problems of the Single Buyer model. It is clear that the Single Buyer model implemented in Mongolia, apart from relying on central planning for decision making, is not suitable for introducing competition and does not promote accountability of the electric companies for complying with their obligations and operate efficiently in the long run. For instance, the payments to the Gencos depend on the amounts collected by the Discos, which are consistently below the amounts due. In fact, some of the electric utilities that we have interviewed have the same opinion regarding the need to abandon the Single Buyer model. It is certain that a market structure based on bilateral supply contracts is more suitable for evolving to a competitive market.

Advantages of competitive markets: Competitive markets substitute central planning and price regulations by competitive forces that foster decentralization, efficiency in operation and development and accountability of the agents. The existence of unregulated supply prices, in a competitive environment, guaranty that sellers and buyers will always agree on prices and supply conditions that will allow the development of the most efficient power plants required by the market. The world experience has shown that competitive structures, if well designed, can be applied both in large and in small electric system [9].

\section{Conclusion}

For improving the efficiency of the energy sector, it is important to continue liberalization policies and ensure the mirror openness. Although the model with a "Single Bayer" is being implemented quite successfully, the overall performance of the industry is improving at a relatively slow pace.

Retail competition is far too costly and carries a significant risk at this time in Mongolia. Wholesale competition is the favored market model as it provides a reasonable balance of the objectives of the market reform effort with reasonable cost and risk while maintaining the flexibility to move to retail competition if and when it is desirable in the future.

In the articles $[10,11]$ the proposed pricing mechanism generates four component electricity prices that relates to an annual average power, deviation from the seasonal average power, electric power deviations from the weekly and daily respective averages. The number of component prices can be either increased or decreased depending on the desired accuracy or other purposes.

\section{References}

1. S. Stoft, Power System Economics: Designing Markets for Electricity, Wiley-IEEE Press; 1st edition, P. 496 (2002)

2. D. Kirschen, G. Strbac, Fundamentals of Power System Economics, Wiley-IEEE Press; 2nd Edition, P. 344 (2004)

3. A. Creti, F. Fontini, Economics of Electricity Retail Markets, in Economics of Electricity: Markets, Competition and Rules P. 235-258 (2019)

4. In-Depth Review of Energy Efficiency Policies and Programmes: Mongolia, Energy Charter Secretariat P. 126 (2011)

5. In-depth review of the investment climate and market structure in the energy sector of Mongolia, Energy Charter Secretariat P. 98 (2013)

6. Ts. Erdenetsetseg, B. Batzaya. Competitive electricity market of the Mongolian Central Energy System // Proceedings of the 11th international forum on strategic technology P. 258-261 (2016)

7. B. Batzaya. Mongolian competitive electricity market // Aspire to science P. 136-137 (2016)

8. National dispatching centerhttps://ndc.energy.mn/?p=263

9. Proposed competitive electricity market design for Mongolia's Central Electricity System (2008)

10. B.Batzaya, V.G. Kitushin, Ch. Ulam-Orgil Method of defining the operational regime of power plants under market conditions, pp. 230-234 (2016)

11. V.G. Kitushin, F.L. Byk, B. Batzaya Pricing mechanism "the year ahead" for model "single buyer” 4, pp. 27-35 (2014) 